\title{
Green procurement model using petri nets: a perspective developed from the models applied to the supply chain
}

\author{
L. M. Guevara Ortega, L. Rodríguez Urrego, D. Gómez Gutiérrez \\ \& J. G. Chenet \\ University EAN, Colombia
}

\begin{abstract}
Currently, developed countries have been implementing sustainable development policies specifically in Sustainable Consumption and Production (SCP). Therefore, companies consider the products and services life cycle, where Green Procurement (GP) represents a key tool for sustainability in the Supply Chain (SC). Moreover, the future on green policies in countries like Colombia has a long way to go on issues such as energy production, consumption and processes within the supply chain. In the GP area, there are three relevant issues in sustainable development policies in Colombia: 1) issues linked to barriers in the implementation such as tariffs, taxes, incentives and promotion; 2) motivation and drivers for the implementation for both public and private sector and 3) performance impacts related to the models used in order to implement in companies. The latter one is the main interest of this paper. Regarding this work, it identifies the mathematical models most widely used in SC processes, especially the issues associated with purchase processes, selection and hiring of suppliers in large and medium-sized enterprises; public or private. Moreover, the paper analyzes the models regarding their advantages and disadvantages on which some of these can be used in GP processes due its high impact. Finally, a possible mathematical model used in GP processes based on petri nets (PN) for to their characteristics and application in complex systems.
\end{abstract}

Keywords: green procurement, petri nets models, green policies, sustainability supply chain. 


\section{Introduction}

In today's world, the internationalization of the markets, technologies and ways of communication makes the definition compulsory of criteria and standards linked with prevention and mitigation of pollution in productive units as well as for environmental preservation. Thus, there is a growing interest for an efficient management of the supply chain and for a better understanding of the specific conditions required to enter several markets. The tendency to the globalization of the production also forced the companies to find out efficient ways of coordination for the materials inside and outside the company, for the reason that we compete today on a timeline and quality basis (Mentzer et al. [1]).

The Rio+20 Conference dealt with topics related to environmental treatment as a central axis for green economy. This close up made modifications on the general landscape for traditional developments, establishing three interrelated political dimensions. The first one is an inversion on sustainable management of the resources, the second one is establishing regulatory and market conditions according to the surrounding and the third one is enhancing the management and involving the private sector giving support to the small and medium-sized enterprises (Hernández [2]).

The public sector promoted the sustainable hiring and public administrations are stimulating the companies for the development of sustainable policies.

The companies who put into practice the policies of sustainable development show positive impacts when it comes to application. In addition, these initiatives also look for cost reduction, better corporate image, reduction of the risk of normativity incompliance, and an environmental differentiation of the products (Rao and Holt [3]).

The studies identified several strategies within the processes of sustainability, and there exists several applications such as LEED certified corporate buildings with improvements for natural resources consumption through so-called green buildings; looking for a better exploitation of the solar energy, environmental degradation management systems and waste management (Vergara et al. [4]).

To make this process real, the first step is green procurement, as starting point in the sustainable supply chain. This paper establishes the importance and possible implications created by the abovementioned process, seen from the applied models related with processes that deal with green procurement such as: supply chain, and supplier selection, among others, for the development of a new general model applied to green purchasing using PN.

This paper has the following structure: in the second section, there is a short review on sustainable supply chain, an analysis of the more relevant models realized by different researchers on sustainable supply chain through PN. The third section does have a description of the green purchasing and progress on this topic. Likewise, this section shows a proposal of a process model for green procurement, through CPN. Our objective is to demonstrate that the beneficial potential towards sustainability in the use of good practices of the green procurement in the private sector. Finally, there are recommendations and conclusions of the research. 


\section{Sustainable supply chain}

For Srivastava [5], the management of sustainable supply chain is the integration of the environmental thinking in the supply chain (see Figure 1). This is integrated into the design of the products (green design), the obtainment and selection of materials (green purchasing), the manufacturing (green manufacturing), the delivery of the final products to the clients (green logistics) and the management of end of life of the products after use (reverse logistics).

There exists a great number of researches in this direction and a number of review papers have contributed to theoretical and practical development of the management of the green supply chain (Seuring and Muller [6], Carter and Rogers [7], Sarkis et al. [8], Ali and Searcy [9], and Ashby et al. [10], and others). After Hoek [11], there is a division in actors of the GrSCM into: a) upstream (raw material providers, information services), b) midstream (companies producing or offering the services that are the central axis for a green supply chain) and c) downstream (clients, distributors, importers, retailers). In our case study, we will focus on the upstream part.

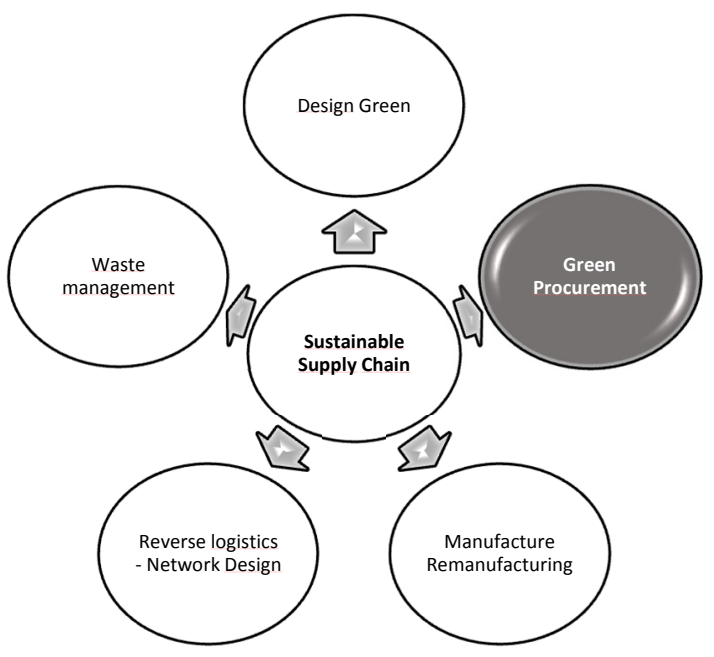

Figure 1: $\quad$ Sustainable supply chain - adapted from Srivastava [5].

\subsection{Sustainable supply chain models using petri nets}

Using the models in the sustainable supply chain allows us to find optimal and pseudo-optimal solutions to different problems where it is required maximizing the efficiency and minimizing the resources and minimizing the time of the operations. The models are a simplified abstraction of the reality and the research mentioned gives the differences between conceptual models, defined as a set of suitable concepts to represent real life objects and the qualitative model based in 
a set of variables and its causal relationship (Tang and Zhou [12]). The analytical models used and a state-of-the-art of the research is presented below.

The first model (De la Fuente Aragón and MacDonell [13]) was an inverse logistics process in PN. The management of the returns, as the case of product return generates difficulties for the direct sales companies, as for the email and ecommerce companies. For this reason, we used two tools in the models: YASPER and HPsim.

The second model developed by Viswanadham and Raghavan [14] designs a dynamic modeling technique for the analysis of nets for the supply chain using stochastic petri nets (GSPN). The model takes into consideration the procurement process and delivery logistics.

The third model is an approach of PN for green supply chain of Pan and Wu [15]. This research studied the focus of the PN considering all the green supply chain as a dynamic system with discrete events and complete stochastic focus.

\subsection{Petri nets}

Different research has been made over the supply chain through quantitative tools with analytical methods, heuristics and metaheuristics, likewise PN models. Carl Adam Petri (1962) developed PN for modeling computer systems and communication protocols. PN are used for modeling telecommunication networks and systems, complex systems, and others such as fault diagnosis in manufacturing defects for preventive maintenance routines (Rodríguez et al. [16]).

The PN are a graphical tool that "...allows modeling systems easily with concurrent, asynchronous, distributed, parallel and/or stochastic events." (Murata [17]). These PNs are based on mathematical modeling, and are suitable for describing concurrent, either synchronous or asynchronous systems, making them ideal for interaction processes and multivariable modeling.

Tools such as PN have proved its effectiveness in DEDS and more recently its extension to modeling hybrid systems (Jensen [18]). The formalism provided in concepts such as synchronism, concurrency, mutual exclusion, and sharing resources are of particular interest and have provided greater representation capacity and power in resulting models, that by FSM.

Additionally, PN contribute to the ability of applying techniques for merging places that allow reducing the size of the resulting models. This synthesis capability in model representation stands out in CPN [18], which allows the application of merging techniques to model different concurrent processes in the same graphic structure of the PN. Moreover, functions with lineal transformations can be assigned to CPN transitions and that implies a big functional variability. A colored petri net $(\mathrm{CPN})$ is a sextuplet. $C P N=$ (P,T,Pre,Post, $\left.M_{o}, C\right)$, where $P$ is a set of places, $T$ is a set of transitions, Pre and Post are input and output functions, $M_{O}$ is the initial marking and $C=\left\{C_{1}, C_{2}, \ldots, C_{n}\right\}$ is the set of colors or marks assigned to different identifiers. An ordinary PN can be folding a CPN, which demonstrates the representation power for complex models, conserving the manageability and legibility of the modeled system. 


\section{Green procurement}

Green procurement, defined by Zsidisin and Siferd [19] is "the set of purchasing policies held, actions taken, and relationships formed in response to concerns associated with the natural environment". GP is known also as eco-procurement or environmentally sustainable and socially responsible buying (Drumwright [20]).

The green procurement process (see Figure 2) consists of subprocesses that are critical to its performance and start at the requisition of goods or services ending in the satisfaction of the end user. The process is described in more detail in section 3.2.

Green procurement presents advances at public and private levels in the United States. The Commission for Environmental Cooperation (CEC) of North America is responsible for the green procurement initiative through the CEC's strategic plan for 2010-2015. The plan contains the projects aimed for improving the environmental performance in the private sector through the exchange of best practices and technologies in the private sector to strengthen local capacity.

In Europe, there are seven countries with significant advances in green purchases (Finland, Sweden, Holland, Germany, United Kingdom and Denmark). The other countries in the EU have approved national plans for green purchases while others are only starting on this topic (Unión Europea et al. [21]) .

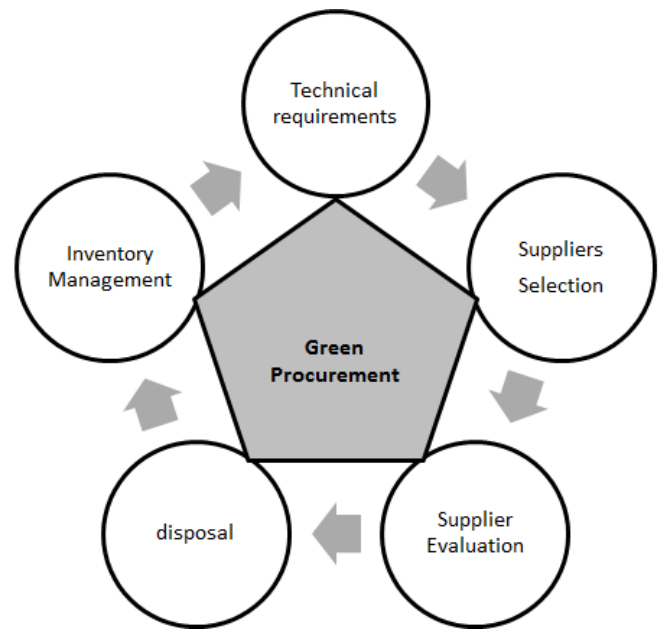

Figure 2: The green procurement process.

According to Saavedra [22] it is observed that for some Latin-American countries the participation of green products in public procurement is inequitable. Part of this phenomenon is explained by the type of good or service demanded by each country and which cannot be offered by SMEs. The tools for sustainable procurement have been strengthening in Latin America and the Caribbean. Each country must address them in the life cycle of the product and service in an integrated form (i.e. specifications, risk analysis, vendor selection, 
evaluation and awarding criteria). To comply with these policies Colombia established among its goals the ones in the National Policy for Sustainable Production and Consumption. This policy states that for the year 2019 there must be an increase of $40 \%$ in the number of companies reporting environmental and social indexes in internationally verifiable and recognized systems Ministerio de Ambiente y Desarrollo Sostenible [23]. In the case of Bogota, a bill for green procurement was approved to help companies strengthen their procesess (Beláustegui [24]).

\subsection{Green procurement model using petri nets}

As a model of GP is used platform models such as the GEMMA (Guide des Modes d'Etude et d'Arrêts Marches), universal tool for process automation called Guide Studies start, stop and Diagnosis of Automated Systems "GEMMAD" (Moreno and Peulot [25]). Green supplier selection criteria may be developed with intent of focusing on meeting government regulations, focusing on process improvement, and focusing on buying company's environmental policy. Humphreys [26] categorizes the green criteria into two groups of qualitative and quantitative criteria (see Figure 3), among others; they are fundamental to the design for the colored GP process.

Within the practice of $\mathrm{PG}$, we distinguish three tasks: a) reduction of resources associated with the minimization of waste, b) re-use of a product or component in the same way without going through the process of remanufacturing to be used c) recycling, collection, processing and manufacture of materials for the creation of new products (Zsidisin and Siferd [19]). The GP process begins with the evaluation of the technical requirements of product or service, then selecting and evaluating suppliers that meet technical and environmental requirements and then the hiring process is performed. The supplier must ensure the provision if the end of life of the product is required to comply with environmental regulations.

The organization must evaluate how it will be buying or hiring, taking into consideration environmental components related to the procurement process (see Figure 3). The company must have clear rules for selecting and evaluating suppliers and/or contractors that have significant impact on the supply of goods or services with significant environmental impact in the life cycle. In addition, it should create a plan for suppliers to meet the criteria for qualifying suppliers on green procurement issues, creating strategic alliances to improve its processes and performance.

\subsection{Colored petri nets applied to green procurement}

In Figure 4 our proposed model used for the process of green procurement, a GPCPN is:

$$
G P C P N=\left\{P, T, \text { Pre, Post, } M_{0}, C, P L N, P L N u, P S S\right\}
$$

where

$P$ is a finite set of places, $T$ is a finite set of transitions, Pre and Post are the input and output arc functions with an additional argument $C_{k}$ that is the color of the 


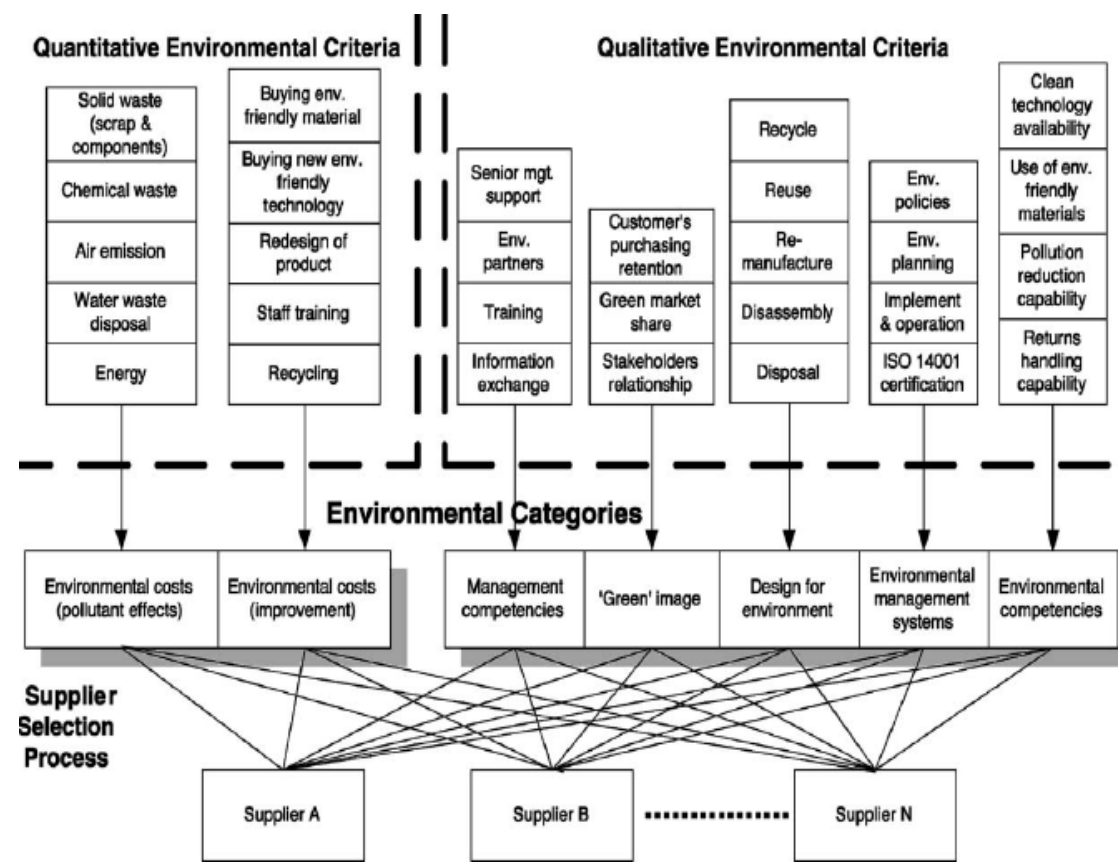

Figure 3: Environmental criteria into the supplier selection process (Humphreys [26]; Akili [27]).

transition firing $T_{j}$. Thus: Pre $\left(P_{i}, T_{j} / C_{k}\right)$ and Post $\left(P_{i}, T_{j} / C_{k}\right)$ correspond in the general case to a linear combination of token colors related to place $P_{i} . M_{0}$ is the initial marking.

$P L N \subset P$ if there is one or more services in place require $P_{i} \epsilon P$, this $P_{i}$ is called $P L N$.

$P L N u \subset P$ there is one or more service suppliers or requirements in place Pi $\epsilon P$, this $P_{i}$ is now called $P L N u$. $C$ is the color set assigned to different identifiers. $C=N \cup S \cup U$. When $N$, is the subset of colored tokens representing the normal system behavior.

$S=\left\{S_{1}, S_{2}, S_{3}, \ldots, S_{n}\right\}$ representing the set of possible services tokens in the database.

$U=\left\{U_{l}, U_{2}, U_{3}, \ldots, U_{m}\right\}$, represent the available suppliers tokens.

$S U=\left\{S_{l} U_{l}, S_{l} U_{2}, S_{2} U_{l}, S_{2} U_{2}, \ldots, S_{n} U_{m}\right\}$, the union $S \cup U$ accounting service tokens required and selected supplier.

$P L N$, it is the place of latent nesting of services.

$P L N u$, it is place of latent nesting of suppliers.

Two major transitions can be seen in figure 4 . The transition $T_{4}$ can be fired only for the color $<S_{1}, \ldots, S_{n}>$ where $n$ is according to the number of possible services. Likewise, the transition $T_{5}$ can be fired only for the color $<S_{1} U_{1}, \ldots, S_{n}$ $U_{m}>$ where $m$ is according to the number of possible suppliers.

PSS is the place of choice of providers (see Figure 4). The qualification criteria for the supplier selection in PSS are qualitative and quantitative. 


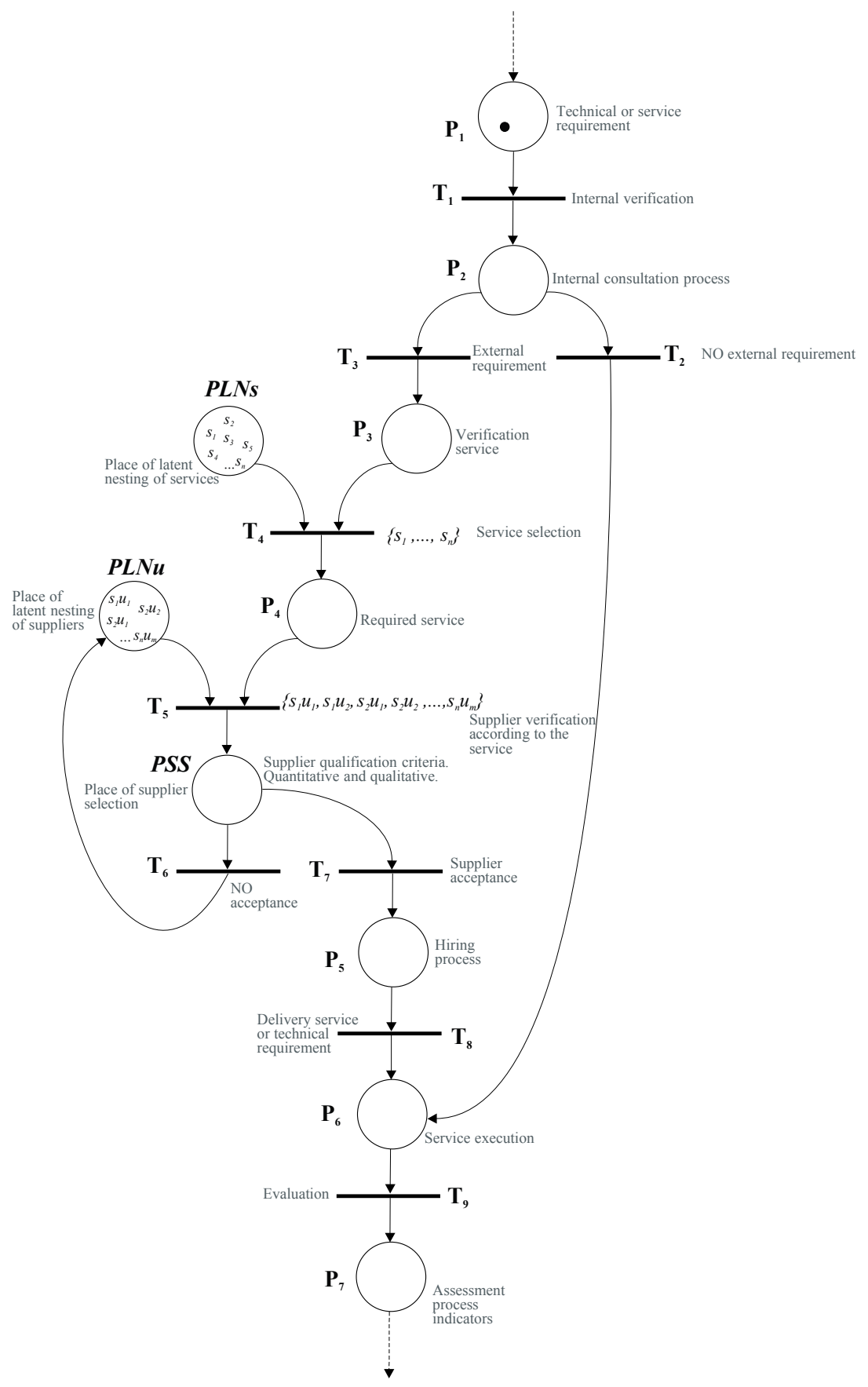

Figure 4: Colored petri net applied to green procurement - GPCPNs. 
In addition, to evaluate the selection of suppliers fuzzy logic for quantitative aspects are used.

With the use of quantitative tools qualitative, can identify the relevant issues to consider in the selection of suppliers for achieving green criteria for organizations to be competitive and meet the standards established in GP for each country

\section{Conclusions}

The proposed model, "GPCPN" colored petri applied to green procurement, present an excellent solution, meeting the objectives that the green procurement process begins with the evaluation of the requirements, ending in the satisfaction of the end user. It is important to make future research aimed into accounting the qualitative and quantitative aspects of green procurement process depending on how an organization is using environmental management strategy. Both groups of criteria may be used at the same time to achieve compliance with standards and competitiveness of organizations.

Colored petri nets applied to green procurement model allows great flexibility to handle many services as necessary in the organization. It also allows a database with all service providers as necessary. However, it is important to supplement the model with the entry of new services and suppliers as a minimum requirement in accordance to environmental policies.

\section{References}

[1] Mentzer, J., DeWitt, W., Keebler, J., Min, S., Nix, N., Smith, C. and Zacharia, Z.G. What is supply chain management, Supply Chain Management, Sage, Thousand Oaks, CA, pp. 1-25, 2001.

[2] Hernández, G. Ayuda para un desarrollo verde: El diseño de la Facilidad de Inversión en América Latina de la Unión Europea, 7-21, 2013.

[3] Rao, P., and Holt, D. Do green supply chains lead to competitiveness and economic performance? International Journal of Operations \& Production Management, 25(9), 898-916, 2005.

[4] Sintana E. Vergara, Damgaard A., and Gómez D. The Efficiency of Informality Quantifying Greenhouse Gas Reductions from Informal Recycling in Bogota, Colombia, 3-5, 2015.

[5] Srivastava, S. Green supply-chain management: a state-of-the-art literature review. International journal of management reviews, 9(1), 53-80, 2007

[6] Seuring, S. and Muller, M. From a literature review to a conceptual framework for sustainable supply chain management. Journal of Cleaner Production 16(15), 1699-1710, 2008.

[7] Carter, R. and Rogers, D. A framework of sustainable supply chain management: moving toward new theory. International Journal of Physical Distribution \& Logistics Management, 38(5), 360-387, 2008. 
[8] Sarkis, J., Zhu, Q. and Lai, K.-H. An organizational theoretic review of green supply chain management literature. International Journal of Production Economics, 130, 1-15, 2011.

[9] Ali, P. and Searcy, C. Comparative literature analysis of definitions for green and sustainable supply chain management. Journal of Cleaner Production, 52, 329-341, 2013.

[10] Ashby, A., Leat M. and Hudson-Smith, M. Making connections: a review of supply chain management and sustainability literature. Supply Chain Management: An International Journal, 17(5), 497-516, 2012.

[11] Hoek, R. From reversed logistics to green supply chains. En: Supply 23Chain Management: An International Journal. Vol. 4, No. 1. 129-135, 1999.

[12] Tang and Zhou. Research advances in environmentally and socially sustainable operations. European Journal of Operational Research, 223, 585-594, 2012.

[13] De la Fuente Aragón, M., and MacDonell, L. R. Aplicación de Redes de Petri para la modelización de procesos en Logística Inversa. In XIII Congreso de Ingeniería de Organización: Barcelona, 466-475, 2009.

[14] Viswanadham, N., and Raghavan, N. Performance analysis and design of supply chains: a Petri net approach. Journal of the Operational Research Society, 1158-1169, 2000.

[15] Pan, M., and Wu W. A. Petri Net Approach for Green Supply Chain Network Modeling and Performance Analysis. In Business Process Management Workshops. Springer International Publishing, 330-341, 2014.

[16] Rodríguez, L., García, E.,Morant, F., Correcher, A. and Quiles E. "Hybrid Analysis in the Latent Nestling Method Applied to Fault Diagnosis" IEEE Transactions on Automation Science and Engineering. vol. 10, no. 99, 116, 0 DOI: 10.1109/TASE.2012.2229706, ISSN: 1545-5955

[17] Murata, T. Petri nets: Properties, analysis and applications. Proceedings of the IEEE, 77(4), 541-580, 1989

[18] Jensen, K. "Coloured Petri Nets 1: Basic Concepts, Analysis Methods and Practical Use". EATCS Monographs on Theoretical Computer Science. Berlin, Germany: Springer-Verlag, 1992.

[19] Zsidisin, G. and Siferd, S. P. Environmental Purchasing: A Framework for Theory Development. European Journal of Purchasing y Supply Management, 7(1), 61-73, 2001.

[20] Drumwright, M. Socially Responsible Organisational Buying: Environment Concern as a Non-Economic Buying Criteria. Journal of Marketing. No. 58 1-19, 2007.

[21] Unión Europea - Fondo Europeo de Desarrollo Regional y Gobierno de Aragón. Compras Verdes. Compra y Contratación Pública Verde en Aragón. 2 Catalogo de criterios productos y proveedores, 13, 2013.

[22] Saavedra, J. Mejora en el acceso de las mipymes a las compras gubernamentales a través de reforma en los mecanismos de compra del 
sector público. Universidad Nacional de San Martín, IDRC, Programa ICT4GP, Documento de Trabajo, (2), 15-50, 2011.

[23] Ministerio de Ambiente y Desarrollo Sostenible. Avances en la implementación de las compras públicas sostenibles en Colombia. 2013. www.mincit.gov.co/descargar.php? $\mathrm{id}=68367$, recuperado el 10 de noviembre de 2014.

[24] Beláustegui, V. Las compras públicas sustentables en América Latina, 2011. https://www.oas.org/es/sap/dgpe/pub/compras2.pdf. Recuperado el 10 de mayo de 2014.

[25] Moreno, S., and Peulot, E. Le GEMMA: modes de marches et d'arrêts, GRAFCET de coordination des tâches, conception des Systèmes Automatisés de Production sûrs. Casteilla, 255-256, 1997.

[26] Humphreys, P. Integrating environmental criteria into supplier selection process. Journal of Materials processing technology (138), 349-356, 2003.

[27] Akili, E. "Green Supplier selection criteria." Supply Chain Systems. facstaff.uww.edu/prasads/761Green/Select.pdf vol 36.4, 7917-7927 2009. 